\title{
Logical Analysis of Parmenides Concept of True Being
}

\author{
Oksana Nevdobenko \\ Bauman Moscow State Technical University \\ 5/1, 2nd Baumanskaya St. \\ Moscow, Russia 105005 \\ E-mail: oksnev@yandex.ru
}

\begin{abstract}
The article analyzes the central concept of Parmenides philosophy, i.e. true being. One of the possible representations of this concept is its interpretation as a logical law, namely, the law of identity. However, there are different ways of representing this law, determined by a selective logical analysis of language expressions. In this work, these approaches are analyzed and compared. The study introduces such an interpretation of the law of identity that satisfies the properties of Parmenides's true being - conceivability and uniqueness.
\end{abstract}

Keywords-knowledge; being; true being; the law of identity; self-applicability

\section{INTRODUCTION}

The investigations in Parmenide's philosophy can be slipped into two sectors. The first one deals chiefly with a linguistic level of analysis. The other is preoccupied with the task of adequate philosophical reconstruction of Parmenide's thought. In this paper, we shall take the latter approach.

In my opinion any reconstruction of the ideas of this philosopher should face and answer (at least) these two tricky and crucial questions.

(I) What did Parmenides mean while saying the famous words: "For it is the same thing that can be thought and that

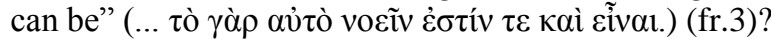

(II) The second crux is again the point of innumerable discussions. This is, for instance, how Gurthrie formulates it: "Why should Parmenides take the trouble to narrate a detailed cosmogony when he has already proved that opposites cannot exist and there can be no cosmogony because plurality and change are inadmissible conceptions?" $[1, \mathrm{p} .5]$. And then he continues: "These are the most baffling problems which Parmenides presents: the nature of the "Way of Seeming" and the relation between it and the "The Way of Truth. Yet the essence of his remarkable achievement lies, as might be expected, within the Way of truth itself." $[1, \mathrm{p} .6]$ There is a good deal of common sense in the assumption of the same author: "To ask: "But if it is unreal, what is the point of trying to give an account of it at all?" is to put a question that is not likely to have occurred to him' [1, pp.5-6] Yet even in this case the question about a coherent philosophical intuition combining two ways of the epic is still valid.

In this paper we deal only with the first question. The second point is going to be investigated in the next paper.

\section{PARMENIDES' CRITERION OF THE TRUE BEING}

The term "being" (einai) first appears in Parmenides's epic "On Nature", where a strictly rational interpretation of this concept is undertaken and the axiomatic construction of the system is first proposed.

Let us recall one of the key points of Parmenides' methodology in analyzing the concept of being, i.e. what really exists. The main drawback of the world of sensory perception, which is so serious that this drawback results in problems concerning the status of this world as existing, is its logical inconsistency. The world of mortals is bad because Parmenides says that it "exists and does not exist" (A fr.40). Furthermore, he explains this idea with examples (in this world there is birth and death, change of place in space, color change) (A fr. 40, 41). It can be seen from the examples that Parmenides associates the problematic nature of the existence of an object with the possibility of accepting incompatible properties by an object, which either formally or indirectly contradicts the formulation (A and not-A) and (A and B. But if B, then it is not. Hence, $\mathrm{A}$ is not $\mathrm{A}$ either) respectively. Hence, according to Parmenides, the criterion of the true being is the logical consistency of its description. This criterion immediately makes the concept of being and, consequently, the problem of its finding non-trivial. (As noted by W.K.C. Guthrie [1, p.120], "The achievement of Parmenides was to demonstrate by logical argument that Being and Becoming were mutually exclusive.").

The modern research points to the relevance of the logical tools for a satisfactory reconstruction of Parmenides's ideas. Let us single out Palmer's fundamental work [2] as an example, in which he clarifies Parmenides epistemology and ontology through the innovative introduction of necessity, inability and chance.

In this paper, several possible logical reconstructions for Parmenides's being are introduced. 
As an axiom, Parmenides takes the conjunction of two statements: there is being, and there is no not-being ("There is only "To Be," and "Nothing" does not exist", fr. 61). The first part of the conjunction can be regarded as an analytically true statement with the most poorly (non-empty) subject. As for the second part, it can also be regarded as an analytical statement with a contentedly poorest empty subject ${ }^{2}$. However, the characteristic of the "emptiness" of Parmenides's being is refuted by the text, where he speaks more about its maximum saturation, such density or "continuity", in which no divisibility is possible (A fr. 24, 25). All properties of the object about which it is said that it does exist (and nothing else is known) are deduced, and this unknown $\mathrm{X}$ appears to be with the necessity: the only, eternal, uncreated, indestructible, not having any parts, immovable.

\section{SEARCHING FOR A TRUE BEING: LOGICAL OPPORTUNITIES}

Thus, we have a descriptively defined object. Given that any appeals to sensory data are methodologically forbidden, how can you bring it closer to some intuition? (All that we have in this respect is intuition (lexemes) "being" and others associated with it ("being", "not-being")). What sort of unique object: effectively known only logically (by reason, according to Parmenides), unchanging, eternal, not having parts? How can you point to it not metaphorically (that it is a ball)?

As candidates for this refinement, proposed by the researchers, we mention two. The only, immutable, immovable being is God (indeed, by these signs very reminding of the God Xenophanes, not without reason the latter is sometimes referred to as Eleatic). The second clarification: true being is the law of identity. We will be interested in the reconstruction of the second option. Le u's move on to it.

Let us note that Parmenides methodology itself deduces to the true being as the law of identity [3]. This methodology is clearly expressed in the program setting "to think and to be are the same things" and indirectly restored by Zeno's paradox, specifying what "thinking" means. Zeno does not think those concepts exist, whose analysis leads to a logical contradiction. Zeno's paradox clearly shows that for Eleatic philosophers to "think", which stands in the identity of being and thinking, means to think logically without contradiction. Thus, it is enough, as was said above, once you accept incompatible predicates and you do not exist, you are only a "name", without the reality behind it:

... just a name,

... everything that is and is not, is born and dies,

The place changes its own and changes bright colors. (Parmenides, On Nature fr.8: 38, 40-41)

Hence, there follows an immediate elimination from the realm of being of all sensually perceived [4].

If you put forward a demand: there exists only that which stands the logical analysis (in the sense of logical consistency), then the only thing to be done is to ontologize logic, (logical) method. The minimum requirement of consistency is the observance of the principle of noncontradiction3. The usual, simplest expression of a logical contradiction: A and not-A. From a logical point of view, it is not true $\mathrm{A}$ and non- $\mathrm{A}$ match $\mathrm{A}$ is equivalent to $\mathrm{A},(\mathrm{A} \& \mathrm{~A})$ matches (A A). The fact that these things are equivalent can be justified by a short chain of reasoning. The identity of these structures was realized and was important for the Eleatic. In general, all logical tautologies are equivalent to each other. It is possible that this intuition (but certainly not exactly the thought itself) is contained in the words:

... one for me and the same -

Here to begin or there: all the same I will turn back I again. (fr.5)

At least, the way of justification from the law of contradiction to the law of identity and the reverse, apparently, was quite obvious for Parmenides. Thus, the candidate for true being must fulfill the propositional principle of identity $(\mathrm{A} \rightarrow \mathrm{A})$, possessing always only compatible predicates. Only in this case the variant of identity is true.

Let us consider in more detail these two versions of the law of identity as candidates for Parmenides's true being.

Propositional formulation of the law of identity. A $\leftrightarrow A$ ( $\mathrm{A}$ is equivalent to $\mathrm{A}$, where $\mathrm{A}$ is a parameter for the statement). In logical theories, as it is well known, $\mathrm{A} \leftrightarrow \mathrm{A}$ is a conjunction of the same formula: $(\mathrm{A} \rightarrow \mathrm{A}) \&(\mathrm{~A} \rightarrow \mathrm{A})$, which is equivalent to simply $(\mathrm{A} \rightarrow \mathrm{A})$, therefore the propositional law of identity in formal logical theories reduces to a conditional connection: $\mathrm{A} \rightarrow \mathrm{A}$. In this version of the law, from the point of view of the theory of semantic categories, A is an expression for the category s (statementdefining category) or general: category $\alpha / \mathrm{s}$ (the category of expressions generating statements).

Predicative formulation. $\mathrm{a}$ is a, where $\mathrm{a}$ is an expression of category $n$ (name-generating category), or a common $\alpha / n$ (the category of expressions that generates names).

In both cases, we have a record with a parameter, that is each of these records is an incomplete expression, it will not formulate any thought, which is not very pleasant. Still, if we have the identity of being and thinking, then as a being it would be desirable to have a thought (at least formal), and not a statement-generating construction. An easy way to solve this problem (which cannot be considered purely formal in the context under discussion) is to somehow forbid the substitution in place of A (or a). There are various operations whose use prohibits substitution (for this parameter), for example, quantification. Indeed, just by hanging a quantifier, we get the completed thought:

For any $\mathrm{A}$ it is true that $\mathrm{A}$ follows from A, or for any a (a is a) 4. Let us fix this possibility. But note that this simple and seemingly quite acceptable solution in this case does not seem to be successful. Logically, an expression with a quantifier immediately complicates its interpretation by an order of magnitude, and Parmenides' intuition sees true being 
as something simple. (As well as his deduction leads to the indivisibility of being.) In addition, the problems of interpreting quantifiers are technically too complex for Parmenides (his time of living) [5]. And they would have to be discussed if we had stopped on a quantitative version of the laws.

Let us talk about what are the variants of $\mathrm{A} \rightarrow \mathrm{A}$ and "a is a" as a true being.

In the first case, Parmenides's true being is a particular case of a cause-effect relationship, its reflexive variant: "to follow from yourself." In the second one, true being is a predicate of self-identity: "to be oneself."

Another way to convert records with parameters to a completed idea is to replace the parameter with an expression with a constant value [6].

What actually can be plugged in instead of the parameter (A or a) in the law of identity?

Variants of the answer.

1) Any other formula / term (= name-forming expression). (Then, as a result of the substitution, we can have, for example, such variants of the law: for example, $(\mathrm{A} \rightarrow \mathrm{B}) \rightarrow$ $(\mathrm{A} \rightarrow \mathrm{B}),((\mathrm{A} \rightarrow \mathrm{B}) \rightarrow \mathrm{A}) \rightarrow((\mathrm{A} \rightarrow \mathrm{B}) \rightarrow \mathrm{A}) \mathrm{f}(\mathrm{a})$ is $\mathrm{f}(\mathrm{a})$, etc., such substitutions, generally speaking, presuppose the existence of a precisely specified language, it is necessary to understand what can be substituted for A / a, and which character sequences are inadmissible for substitution [7].

2) With the restriction: it is allowed to substitute expressions containing only A / a as a parameter. As a result of the substitution we will have expressions of the type

$(\mathrm{A} \rightarrow \mathrm{A}) \rightarrow(\mathrm{A} \rightarrow \mathrm{A}),((\mathrm{A} \rightarrow \mathrm{A}) \rightarrow \mathrm{A}) \rightarrow((\mathrm{A} \rightarrow \mathrm{A}) \rightarrow$ $\mathrm{A})$, and so on. Criticism from the previous paragraph remains significant. With "a" the situation is more complicated: after substitution, there is a change in the order of the predicate "to be" and, accordingly, its semantic category.

3) Only a trivial permutation is allowed: instead of A we can substitute only A itself (instead of a - a).

The latter option is good for two reasons. First, there is no such obvious need for a precisely defined formal language, within which we will formulate different versions of the law of identity. Then, in the first two cases of identity laws, there are infinitely many that do not coincide with the uniqueness of the object "true being". This disadvantage is not possessed by the third variant, when the identity expression $\mathrm{A} \rightarrow \mathrm{A}$ (or $\mathrm{a}$ is a) is considered as the identity law. But it remains an incomplete thought.

However, we will overcome this shortcoming.

\section{TRue Being AS A Single, Specified Conceivable OBJECT}

There is a variant of the interpretation of the principle of identity, in which a substitution is made for a single object, instead of the parameter A. The completed thought (record) will be obtained if we read the principle of identity as a self- applicable statement. That is if in $\mathrm{A} \rightarrow \mathrm{A}$ we mean $\mathrm{A} \rightarrow \mathrm{A}$ as $\mathrm{A}$, or " $\mathrm{a}$ is a" under a, we will understand the expression "a is a" itself.

With self-applicability, we obtain the uniqueness of the identity principle and the absence of a parameter in the record, that is it will no longer be a record with incomplete information.

Let us put the question like this. What in the context of the Parmenides system can be substituted in the law of identity? What is an expression with a constant value? For the variant "a is a", the only thing we have for substitution is being. First, it is postulated that it exists, and then it is proved that it is unique. Hence, as an object for substitution, which can "close" the gap in a formal record, it is suitable. Nonexistence is another candidate for substitution. But it is illogical, the only thing that Parmenides considers possible to say about it: it is not and it is inconceivable. If so, then it is meaningless to assert (in the Parmenides system) that nonbeing is identical or not identical with itself.

Let us mention here that some authors consider that according to Parmenides there can be no differentiation between thinking and what is thought. The controversy of this position is summed up by Palmer in the following way: "The apparent difficulty for this position is that it leaves the entity (or entities) whose essence is thinking with nothing to think about . If thinking and being are identical, then nothing can be that is not thinking" [2, p.120] Here is some more portion of critique from the same author now taking into account the research presented in [8, 9]: "This difficulty has driven at least one recent interpreter to argue that the entity whose being is thinking is the object of its own thought. Ian Crystal, whose reading of Parmenides is in other respects a fairly conventional representative of the strict monist interpretation, has argued that Parmenides' monism 'entails the strict identification of the epistemic subject and object'. Since Parmenides' arguments in fr. 8 rule out any division or differentiation in what is, there is, according to Crystal, no option for Parmenides but to maintain that there is no 'differentiation between thinking and what is thought' Essentially, Crystal is just highlighting a necessary consequence of taking Parmenides to have been a strict monist: 'the distinction between the thinker and the object is a distinction that cannot be maintained in light of the monism outlined in Fragment 8 because the account on offer there prohibits all forms of differentiation'. Crystal's concluding formulation is that Parmenides 'identifies the cognitive act with what it apprehends'. This purported position is incomprehensible because incoherent. If Parmenidean Being is at once thinking and the object of its own thought, then it already violates the principle of the identity of thinking and being. In so far as it is thought, it is not thinking, so that its being cannot be identical with its activity of thinking but must also consist at least in part in its being such as to be thought." [2, p.120].

We suppose that our interpretation is free from this critique. A logical law is a mental construction, yet it doesn't have to be understood as a sort of a process (thinking), in particular as a self-intellection (which is more general and 
less precise concept). While dealing with logical laws we don't have to put a question of the subject who operates with these laws. Logical laws are both mental and quite impersonal entities.

\section{CONCLUSION}

Thus, in our opinion, the following can be proposed as a reconstruction. The true being of Parmenides, if we understand it as the law of identity in the form "a is a," is the thought "Being is being," where by being itself this expression is understood.

Surprisingly, the understanding of identity as a selfapplicable design is grounded in textual terms, namely, Parmenides's words about being exactly work on this understanding (which at the same time is thinking): "The thought and purpose of this thought [for which this thought]

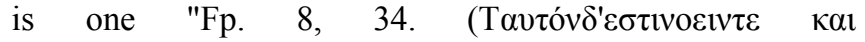

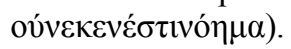

- Any other concepts with an empty denote (for example, a dwarf, a golden mountain) are meaningfully richer. However, the question of comparability in the content of empty concepts is the topic of a separate field of study, where differentiation of non-existent objects is introduced in various ways.

- Usually; we will not take into account the experience of logic of the 20th century.

- and in this case it is a variable, although in formallogical languages this symbol is usually reserved for the role of a constant.

\section{REFERENCES}

[1] Guthrie W.K.E. A History of Greek Philosophy. Vol. 2. The PreSocratic Tradition from Parmenides to Democritus, Cambridge University Press, 1965.

[2] Palmer J. Parmenides and Pre-Socratic, Philosophy Oxford University Press, 2009.

[3] Ivlev V.Yu., Ivleva M.L. Peculiarities of Aristotelian scholastic logic // Proceedings of the 2017 2nd International Conference on Contemporary Education, Social Sciences and Humanities. (ICCESSH 2017). Part of the seriesASSEHR. Moscow, Russia, pp. 91-95.

[4] Lazarev F.V., Lebedev S.A. The Philosophical Reflex: Essence, Form, Types // Voprosy filosofii. 2016. № 6. P. 15-28.

[5] Lebedev S.A. The Structure of Scientific Rationality // Voprosy filosofii. 2017. № 5. P. 66-79.

[6] Ivlev V.Y., Lepskaya N.D. Modalities and logic // Proceedings of the 2017 2nd International Conference on Contemporary Education, Social Sciences and Humanities". (ICCESSH 2017). Part of the series ASSEHR. Moscow, Russia, vol.124, pp.79-86.

[7] Ivlev Y. V., Ivlev Y.Yu., Ivleva M.L. Logical-argumentative basics of educational culture // Proceedings of the 4th International Conference on Education, Language, Art and Intercultural Communication (ICELAIC 2017) PartoftheseriesASSEHR. Moscow, Russia, pp. 173-177.

[8] Crystal I. 'The Scope of Thought in Parmenides' // Classical Quarterly, 2002,52: 207-19.

[9] Crystal I. Self-Intellection and its Epistemological Origins in Ancient Greek Thought // 2002, Aldershot and Burlington, VT: Ashgate. 